\title{
Елена Гладунова
}

- Одесский региональный институт государственного управления Национальной академии государственного управления при Президенте Украины

- e-mail: 7itar@i.ua

- ORCID: 0000-0003-3489-4746

ГОСУДАРСТВЕННАЯ СЛУЖБА В СУДЕБНЫХ ОРГАНАХ ЕВРОПЫ И УКРАИНЫ: СРАВНИТЕЛЬНЫЙ АНАЛИЗ

\author{
PUBLIC SERVICE IN THE JUDICIAL BODIES OF EUROPE AND UKRAINE: \\ COMPARATIVE ANALYSIS
}

\section{| Abstract}

- Goal - to carry out a comparative analysis of civil service in the judiciary of Europe and Ukraine and highlight the positive foreign experience for the possibility of borrowing it in the Ukrainian state.

- Research methodology - the article uses the method of system analysis, an integrated approach, a comparative method, as well as analysis and generalization of practical activities.

- Score/results - the article analyses the organization and functioning of the civil service on the example of some foreign countries. The main similarities and differences in the relationship between the institution of public service and the judicial authorities of Ukraine are highlighted. Ways of functional optimization and problem solution based on borrowing foreign experience are proposed.

- Originality/value - the work was performed by the author independently, without outside help. The article contains links to quotes, as well as links to legislation. In essence, the article is an overview report.

| Keywords: civil service, court, employee, France, Ukraine, prestige, professionalism, reputation. 


\section{1. Вступление}

Государственный аппарат как предмет исследования и реформирования всегда занимал центральное место в государственно-правовых работах в связи с его функциональным назначением. По мнению Н.М. Гринивецкой, «государственная служба обеспечивает прогрессивное участие наиболее способных управленцев, лучших граждан общества в решении тех задач, которые стоят перед общественным развитием и выражаются в функциях государства» [Griniveckaya, 1999: 27]. В координационном аспекте, «государственная служба - совокупность организационной (системы государственных органов, на которые Конституцией и законами Украины возложены полномочия относительно исполнения заданий и функций государства), процессуальной (правил и процедур, установленных законом для принятия на службу, ее прохождение, прекращение) и человеческой (корпуса лиц, которым присваиваются ранги государственных служащих) составляющих» [Gosudarstvennoe upravlenie..., 2003: 281].

На наш взгляд, огромное влияние на формирование и становление института государственной службы, в том числе, в системе органов судебной власти, произвела история, правовые традиции и особенности государственного управления. Хотелось бы выделить схожую с нашей позицию М. Апон, которая считает, что особенности становления и функционирования государственной службы в разных странах во многом определяются самой спецификой их развития. Исследовательница описала ряд факторов, повлиявших на выбор модели государственной службы, таких как:

1) «Специфика исторического развития этих стран (появление и нормативно-правовое регулирование института профессиональной государственной службы).

2) Специфика правовой системы (англосаксонская или романо-германская правовые системы).

3) Специфика государственного устройства (государство федеративное или унитарное, тоталитарного или демократического типа)» [Apon, 2016: 6-7].

По мнению А. Огренчук, «прогрессивный опыт стран ЕС свидетельствует о том, что эффективная организация государственной службы является залогом успешной реализации государственной политики, так как государственная служба - это способ реализации функций социального государства путем совмещения личных, групповых и государственных интересов. Совре- 
менные государства, достигшие высокого уровня экономического развития и социального обеспечения и в то же время соблюдающие демократические стандарты, гарантии и права человека, не могли бы обеспечить достижение этих целей без последовательного и эффективного развития профессиональной государственной службы» [Ogrenchuk, 2011].

Надлежащее совершение правосудия в Украине невозможно без организации его деятельности настоящими профессионалами, полностью удовлетворенными своей работой. Преимущественная часть работников аппаратов, секретариатов судебных органов, которые призваны обеспечивать бесперебойную работу суда и способствовать судьям в осуществлении их главной функции, то есть совершении правосудия - государственные служащие. Их профессионализм направлен на стабильность службы, обеспечение качественного выполнения должностных обязанностей, реализацию заданий судебного органа по оказанию услуг. Таким образом, проведение работы по повышению и поддержанию профессионализма государственных служащих органов судебной власти должно быть одним из приоритетных заданий государственной политики. Добиться этого, по нашему мнению, возможно путем привлечения и использования положительного зарубежного опыта в сфере государственной службы, подтвержденного практикой и временем. Так, с точки зрения И. Назарова, повышение и поддержание высокого уровня профессионализма и профессиональной дисциплины, соблюдение традиций в сфере профессиональной культуры вспомогательного персонала судебных органов и других государственных служащих аппарата суда признаются одним из основных направлений постоянного совершенствования судебной системы и за рубежом, например, в Германии [Nazarov, 2011: 246].

Исходя из вышеизложенного, мы убеждены, что для достижения таких результатов, в частности, в сфере государственной службы судебных органов Украины, необходимо детальное изучение опыта государств, которые своим примером демонстрируют высокий уровень функционирования данного института.

Среди научных исследователей, которые изучали вопрос организации работы государственных служащих судов зарубежных стран, можно назвать: М.Е. Апон, С.Д. Дубенко, В.В. Молдован, И.В. Назарова, Д.Х. Саликова, Е.С. Черноног и др. исследователей.

Однако, большей частью, эти научные работы направлены на функционирование судебной системы других стран в целом и государственной службы в общем контексте, а вопрос организации работы государственных 
служащих в системе органов судебной власти в странах Европы, который может быть полезен и применим в Украине, остается недостаточно исследованным. Таким образом, детальный анализ правового статуса, отбора, карьерной классификации, системы оплаты труда, мотивации работников судебных учреждений зарубежных государств станет залогом дальнейшего заимствования опыта в данном направлении и будет способствовать повышению и поддержанию высокого уровня профессионализма и профессиональной дисциплины института государственной службы судебных органов Украины, как стойкой тенденции его развития.

\section{2. Государственная служба работников судебных органов Франции}

Фокус нашего сравнительного исследования будет направлен на анализ стран со схожими факторами формирования института государственной службы. Украина, как и Франция, является унитарной демократической республикой. Кроме того, эти страны Европы имеют схожую систему общих судов: суды первой, апелляционной и кассационной инстанций. Работники аппаратов, секретариатов судов в Украине в большей мере наделены статусом государственных служащих.

Как определено научным исследователем С.Д. Дубенко, «во Франции к государственным служащим относятся все служащие государства - ее законодательных, исполнительных, судебных органов. Кроме государственной службы, законом 1984 введено также публичную службу местных общин» [Dubenko, 1999: 14]. Схожесть госслужбы Украины и Франции определена иерархией должностей чиновников и наличием категорий, которые включают несколько рангов. Ранги выступают основным звеном карьерной классификации во Франции, они предоставляют право на занятие ряда соответствующих должностей и являются важной гарантией стабильности чиновника. Также ранги могут называться классами. Но при этом, в отличие от Украины, каждый ранг чиновника, в свою очередь, делится на степени.

Исследователи подчеркивают, что «правила поступления на государственную службу определяются Общим кодексом государственных служащих. Чтобы стать государственным служащим и работать в органах власти, необходимо пройти конкурсный (внешний, внутренний) или профессиональный отбор, что, в общем, объединяет с нормативным регулированием отбора госслужащих в Украине. 
Французский государственный служащий должен соблюдать семь основных принципов: полное обязательство по отношению к профессиональной деятельности, нравственные принципы, сдержанность, иерархическая покорность, профессиональная осмотрительность, честность, нейтралитет. Отказ выполнять эти обязательства может привести к дисциплинарным санкциям, вплоть до увольнения (5773 санкций в 2004 году).

Все государственные служащие Франции разделены на три корпуса: государственный, территориальный и госпитальный. Отдельные уставы предусмотрены для парламентариев, магистратов судебной системы и военных. Корпуса состоят из трех категорий: от А до С, в порядке убывания уровня ранга (50\% категория С). Во Франции ранг отделен от должности, то есть государственный служащий связан со своим рангом, а не с должностью» [Mirovye modeli..., 2012: 371].

Как отмечает исследователь Д.Х. Саликов, анализируя классификацию категорий и рангов во французском государстве, «класс А - разрабатывает решения, исходя из политических установок правительства. Класс В исполняет данные решения. Класс C - специалисты, а класс D - вспомогательный персонал, который в 1990 г. фактически объединили с классом С. Классы могут делиться на подклассы. При этом существует деление чиновников на многочисленные корпуса, число которых иногда достигало 1500, что затрудняло создать стройную систему государственной службы. Во Франции публичные служащие делятся на две категории: первая - это гражданские служащие и примыкающие к ним служащие местных учреждений; вторая - полицейские, служащие парламента и других публичных органов, связисты, работники судов и т. п. Вторая категория не регулируется Общим уставом государственных служащих. Их деятельность регламентируется особыми документами, в которых, например, есть ограничения в правах этих служащих (например, запрет на забастовки), но это компенсируется государством материальными факторами для этой категории работников» [Salikov, 2018: 97-98].

Таким образом, в подтверждение ранее обозначенным доводам научных исследователей соглашаемся, что неоспоримым является тот факт, что работники судебных органов Франции, как и преимущественно служащие аппаратов и секретариатов судов в Украине, имеют статус государственных служащих.

По мнению Е.А. Литвинцевой, «суть французской госслужбы заключается в том, что это закрытая и подробно регламентированная система 
администрирования, главными принципами которой являются иерархичность и верноподданность государству. Система госслужбы Франции основывается на принципе специфичности деятельности государственной администрации, что требует наличия профессионального персонала. Служащие, получившие специальную подготовку, продвигаются по служебной лестнице в соответствии с определенными механизмами карьерного продвижения. Такая система организации службы получила название системы карьеры или системы закрытой госслужбы. Карьера характеризуется гарантией занятости для служащих, а также профессиональной мобильностью на все время прохождения службы. Отличительной чертой госслужбы является ее корпоративность, особенно высших чиновников, которая сохраняется и в случае перехода на работу в частный сектор» [Litvinceva, 2003: 56].

Закрытая государственная служба несет под собой стойкую идеологическую основу, которая выражается в восприятии чиновниками госслужбы как особой профессии, построенной на изыскании неординарных человеческих качеств и требующей полной отдачи служению Франции. Государственный служащий убежден, что добросовестное выполнение должностных обязанностей станет залогом его стабильного и постепенно повышающегося материального обеспечения. При этом привлечение и удержание на государственной службе наиболее ценного персонала подразумевает наличие высокого общественного престижа, некой степени элитарности данного института, а также наделение чиновников рядом привилегий (льгот), что обеспечивается государством.

Кроме того, для более детального исследования особенностей института государственной службы Франции считаем необходимым также внести дополнения относительно реализации одной из 5 моделей реформирования государственной службы данного государства. Существуют традиционная, рыночная, участвующая, гибкая и дерегулированная модели, на описании которых в своих трудах останавливаются такие научные исследователи, как Е.П. Лапа [Lapa, 2011: 244] и Ж.В. Грекова [Grekova, 2001: 46]. Речь идет об «участвующей» («континентальной», «закрытой») модели, функционирующей во Франции, согласно которой неформальные механизмы управления государственной службы занимают основную позицию. Одним из видов таких механизмов является репутационный контроль, что значимо в концепции развития человеческого актива. Такой контроль, как элемент социального интеллекта чиновника, позволяет продолжить ему карьеру не только на должности государственного служащего, но и в других сферах. 
Е.П. Лапа выделяет, кроме контроля за репутацией также второй вектор «неформального» регулирования госслужбы, такой как общественный контроль, т. е. одобрение (порицание) деятельности чиновника, как выражение приемлемости (неприемлемости) для массового сознания общественности характерных им конкретных поведенческих форм.

Следует подчеркнуть, что французской судебной системе характерна многогранность судебных органов в зависимости от специализации и юрисдикции, надлежащее функционирование которых обеспечивает институт государственной службы.

Так, В. Молдован, описывая трехуровневую общую судебную систему Франции, отмечает, что «среди судов первой инстанции выделяют трибуналы малой инстанции и суды большой инстанции. На них возлагается рассмотрение и решение основной массы дел, в основном гражданских и уголовных. К трибуналам малой инстанции относятся: полицейские трибуналы, суды упрощенного гражданского процесса, суд по делам опеки». [Moldovan, 2012: 318]. Кроме того, в данной стране существуют исправительные суды, суд по делам несовершеннолетних, суд по патентным делам, суд по делам исполнения решений, дисциплинарная палата, палата по гражданским делам; на уровне судов первой инстанции действуют специализированные суды, такие как: коммерческие трибуналы, торговые трибуналы, суды по делам морской торговли, суды по вопросам социального обеспечения, суды по вопросам земельной аренды. Вторая инстанция судебной системы Франции представлена апелляционными судами, третья - Кассационным судом. Кроме перечисленных судов, в судебной системе Франции действуют Высокая палата правосудия, Палата правосудия Республики и Суд по конфликтам. Также функционирует система административной юстиции, которая включает сорок два административных суда первой инстанции, восемь апелляционных административных судов и Государственный совет (кассационная инстанция), возглавляющий систему административной юстиции, в его ведомстве находится около 2,5 тыс. судей и государственных служащих. «В своей деятельности члены Госсовета опираются на 350 человек обслуживающего персонала, занимающегося приемом и информированием посетителей, общими административными вопросами, профессиональной переподготовкой кадров, социальными вопросами, уходом за фондом недвижимости, техническим обслуживанием системы связи и коммуникаций, документацией, бюджетными и финансовыми вопросами и их контролированием» [Государственный совет...]. 
Также во Франции, «для первоначального состава органов, созданных декретом от 27 января 1970 года, агенты, имеющие статус государственных служащих судов и трибуналов и промышленных трибуналов на дату вступления в силу этого декрета, за исключением главных клерков и секретарей этих юрисдикций, интегрированы в органы, созданные выше, на уровне и ступени, соответствующих выполняемой ими функции и индексу, которым они пользуются, по приказу Хранителя печатей, министра юстиции и министра, ответственного за государственную службу. Услуги, фактически оказываемые государственным служащим судов и трибуналов, а также отраслевых трибуналов, приравниваются к услугам, выполняемым интеграционными органами, для классификации заинтересованных сторон.

Для применения статьи 16 Кодекса о гражданском и военном пенсионном обеспечении должностные лица судов и трибуналов или промышленных трибуналов, кроме главных секретарей и секретарей, приравниваются к должностным лицам органов судебной службы категорий С и D на тех же условиях, как указано в статье 7 для действующих должностных лиц. Совместные административные комитеты должностных лиц судов и трибуналов и промышленных трибуналов, за исключением главных секретарей и секретарей, создаются представителями этих должностных лиц и представителями администрации, действующей 15 марта 1992 года» [Указ № 92-415...].

Исходя из вышеизложенного, можно сделать вывод, что должностные лица судов, кроме судей, представлены, как государственные служащие, занимающие более высокие позиции чиновников и публичные служащие специалисты, выполняющие вспомогательные функции.

Проводя параллель с институтом государственной службы Украины, в том числе в системе судебных органов, следует выделить понятие Agents non titulaires d'Etat, что означает внештатный государственный служащий. Согласно Кодексу административного правосудия Франции «внештатные государственные служащие, не являющиеся должностными лицами, являются публичными служащими, работающими на государственные структуры на основании договора и не обладающими преимуществами, которые дает статус государственной службы» [Francuzskij Kodeks..., 2019]. Важно сделать акцент на том, что дефиницию «внештатный государственный служащий» во Франции нельзя отождествить с понятием внештатного сотрудника, поскольку такой служащий нанимается на работу не для выполнения конкретной, короткой во времени задачи. Характер услуг французского 
внештатного государственного служащего имеет достаточно длительный характер на платной основе для выполнения, например, определенного акта. Применение такого опыта для украинских судов могло бы решить ряд проблемных вопросов с ведением таких участков работы, как тендерная процедура в сфере публичных закупок для организации судебной деятельности, обеспечение охраны труда, сопровождение комплексной системы защиты информации и др., что, в свою очередь, в некоторой мере сняло бы часть нагрузки с руководителей аппаратов судов.

На наш взгляд, следует детально остановиться на рассмотрении должностей работников судебных учреждений Франции.

«Наличие компетентного персонала с определенными ролями и признанным статусом наряду с судьями является важной предпосылкой для эффективного функционирования судебной системы, а именно:

1) функция Rechtspfleger, вдохновленная австрийской и немецкой системами; согласно Европейскому Союзу Rechtspfleger (EUR) - независимый судебный орган, основанный на Конституции и выполнении задач, возложенных на нее законом; Rechtspfleger не помогает судить, но работает вместе с последними и может выполнять различные юридические задачи, например, в сферах семейного или наследственного права; он/ она также имеет право принимать судебные решения независимо от предоставления гражданства, платежных поручений, исполнения судебных решений, аукционов недвижимого имущества, уголовных дел и исполнения приговоров по уголовным делам; он/она наконец, компетентен выполнять административные судебные задачи. Rechtspfleger в определенной степени находится между судьями и персоналом, не являющимся судьей, например, регистраторами;

2) сотрудники, не являющиеся судьями, задача которых заключается в непосредственной помощи судьям. И судебные советники, и регистраторы помогают судье в их судебной деятельности (в частности, на слушаниях) и, возможно, должны будут подтверждать подлинность актов;

3) сотрудники, ответственные за различные административные вопросы и за управление судами;

4) технический персонал, отвечающий за ИТ-оборудование, безопасность и уборку;

5) другие сотрудники, не являющиеся судьями» [European Judicial..., 2012: 146]. 
Таким образом, анализ государственной службы судебных органов Франции предоставляет возможность выделить такие ее особенности:

- ранги, как основное звено карьерной классификации;

- система закрытой государственной службы для профессионального персонала;

- многогранность должностей государственной службы и судебных органов в зависимости от специализации, юрисдикции, инстанционности;

- использование услуг внештатных государственных служащих;

- контроль за репутацией государственных служащих, как эффективный механизм регулирования их деятельности путем сопоставления действий чиновника с ожидаемой оценкой общественности.

3. Анализ государственной службы судебных органов Украины: параллели и противоположности

В отличие от французского государства, в Украине существуют три категории государственной службы: «А», «Б», «В» и девять рангов. К представителям категории «А» в судах относятся: руководители аппаратов (Секретариатов) Конституционного Суда Украины, Верховного Суда, высших специализированных судов, их заместители. Судебные администраторы (руководители аппаратов) и начальники структурных подразделений местных и апелляционных судов, их заместители представляют категорию «Б». Работники аппаратов вышеуказанных судебных органов от секретаря суда до главного специалиста относятся к категории «В».

Ранг в Украине, на наш взгляд, нельзя назвать связующим звеном карьеры государственного служащего. От ранга, как вида специального звания, зависит, в частности, оплата труда. Очередной ранг госслужащий в Украине получает через каждые три года в рамках соответствующей категории, за исключением некоторых нюансов. Категория «А» предполагает присвоение от 1 до 3 ранга, категория «Б» - 3-6 ранги, категория «B» - 6-9 ранги. Законодательство Украины также не предусматривает деление рангов на степени.

Следует сделать акцент на том, что надбавка за ранг является стабильной выплатой, гарантированной государством украинскому служащему. Однако, на сегодняшний день, эти выплаты достаточно скромные. К примеру, надбавка за ранг секретаря суда категории «В» 9 ранга составляет менее $5 \%$ от должностного оклада. 
Анализируя опыт Франции, можно отметить сходство относительно проведения конкурсного отбора на занятие должности государственного служащего.

Хотелось бы обратить внимание на тот факт, что государственная служба Украины строится на ряде очень важных, законодательно определенных принципов. Кроме того, включает значительный перечень обязательств служащего, который во многом соотносится с французским, однако, таких обязательств, как иерархическая покорность, профессиональная осмотрительность, не содержит. Более того, увольнение с должности государственной службы, в отличии от Франции, рассматривается, как исключительный вид дисциплинарного взыскания и применяется лишь в таких случаях, как нарушение Присяги, неуважение к государству, государственным символам Украины, Украинского народу и т.п. Заимствование такого опыта госслужбы Франции, как внедрение более жестких дисциплинарных взысканий, по нашему мнению, применимое в большей мере к чиновникам категории «А», могло бы поспособствовать повышению осознанности государственных служащих высших рангов.

Правовое регулирование государственной службы в Украине обеспечивается Законом «О государственной службе» и другими подзаконными актами. В отличии от Франции отдельных ограничений в правах для определенных категорий госслужащих, как и, в свою очередь, материальной компенсации за соблюдение запретов, нет. Нормативно-правовым актом определены ограничения, равные для всех государственных служащих, относительно участия в забастовках и агитации.

В украинских судах на должность государственной службы секретаря судебного заседания, секретаря суда, судебного распорядителя, главного и ведущего специалистов структурных подразделений, консультанта, руководителя аппарата и т. д. могут претендовать соискатели в области юриспруденции, делопроизводства, статистики, информационных технологий, государственного управления.

4. Кадровый потенциал, методы мотивации и оплата труда на примере стран Европы

«Развитие профессионального и творческого потенциала государственных служащих является одним из приоритетов государственной кадровой 
политики стран ЕС. От кадрового потенциала структур государственной службы напрямую зависит успешное проведение экономических и социальных реформ в государстве.

Процедура найма сотрудников, предусмотренная в системах государственной службы стран-членов ЕС, сочетает в себе два принципа:

1) право равного доступа любого квалифицированного гражданина к государственной (гражданской) службе. Каждый гражданин имеет право занять публичную должность, при условии, что он/она соответствует требованиям, предусмотренным законом, регламентирующим государственную службу, а также требованиям к соискателям на данную вакансию;

2) принцип лучших кандидатов, определяющий заинтересованность структур государственного управления в найме лучших кандидатов на государственную службу.

Принцип равного доступа является определяющим для стран, государственное управление которых сформировалось под влиянием французской концепции (к ним относят Испанию, Италию, Францию). При этом такие страны, как Голландия и Скандинавские страны, отдают предпочтение принципу лучших кандидатов.

В той или иной мере признаки обеих систем наблюдаются в организации государственной службы ряда стран. Так, странами - членами ЕС была разработана система подбора и найма персонала для государственного управления, которая учитывает оба принципа. Хотелось бы отметить, что, например, для Германии характерна специализация государственного служащего, во Франции и Великобритании большее внимание уделяется умению государственного служащего выполнять как административные, так и технические специальные функции. Для ЕС характерен подбор персонала путем проведения тестов, экзаменов, собеседований, а также при помощи посреднических организаций - агентств, за плату осуществляющих подбор необходимых специалистов. Государственный служащий Великобритании должен обладать следующими качествами: высоким интеллектом, умением достигать результата и умением общаться с людьми. Что касается системы оплаты труда государственных служащих, то она направлена на совмещение поддержки общего бюджетного равновесия и обеспечения мотивации служащих. Для стран Европы характерна значительная дифференциация оплаты труда в соответствии с должностью и государственным органом. 
В Германии материальное благосостояние служащих состоит из оклада, территориальной надбавки, надбавок на детей, за выслугу лет и за звание. Размеры, динамика и структура выплат определяются специальным законом. Во Франции определение сетки индексации заработной платы не менялось с 1948 года и связано с понятием валовый индекс (IB - indice brut). Валовый индекс позволяет сопоставлять структуры прохождения службы согласно контингентам государственных служащих Франции» [Ogrenchuk, 2011]. Заслуживает внимания опыт госслужбы Венгрии, который отличен от украинского, в частности. Поскольку, в Венгрии существует пять категорий государственных служащих (агентов): среди которых специалисты юстиции (судьи, сотрудники судов, прокуратур и др.) [Czernorog, 2008: 307]. В Украине, между тем, судьи и прокуроры имеют отдельный статус, не связанный с государственной службой.

Важно отметить, что вознаграждение государственных служащих во Франции включает, кроме платы (оклада) еще и семейную доплату, помощь на жилье и другие выплаты. Кроме того, на служащих распространяется специальные системы пенсионного и социального обеспечения.

Интересным является также международный опыт использования в оплате труда так называемых грейдов, которые выступают в качестве современной технологии мотивации кадров. Среди особенностей их применения выделяют количественный фактор, может быть от 7 до 18 и более грейдов. Кроме того, используются показатели оценки поста работника. Грейдинг на госслужбе разрабатывается на основе классификации должностей, в его контексте оплата труда может зависеть от географического расположения. Также неотъемлемой частью грейдинга является сопоставление уровня оплаты труда на государственной службе с рыночным уровнем. B странах EC, где используется такой вид мотивации персонала, практикуется повышение оплаты труда кадров в пределах грейда без изменения должности на основе стажа работы, прохождения профессионального обучения или получения определенного уровня квалификации, а также периодичной (1 раз в год) оценки результатов деятельности.

Финансирование государственной службы украинского государства гарантировано законом. Фонд оплаты труда формируется из государственного бюджета. Кроме должностного оклада, госслужащим начисляются надбавки за выслугу лет и за ранг. Что касается стимулирующих выплат, то премии могут выплачиваться по результатам работы лишь в случае установления и на основании ежегодного оценивания служебной дея- 
тельности за получение только отличной оценки. Выплаты совершаются в рамках бюджетных ассигнований (общий размер премий по результатам работы (месячных, квартальных) за год не может превышать 30\% фонда оклада госслужащего за год), т. е. зависят от решения законодательного органа.

На наш взгляд, на основании сравнительного анализа следует отметить, что государственная служба в Украине, в частности в судебных органах, в условиях активного реформирования занимает достойное место в области государственного управления. Прослеживается достаточно детальное нормативное регулирование, однако, на сегодняшний день все же присутствуют стороны, которые отличают ее от государственной службы стран Европы, управление которых направлено на строгий отбор высококвалифицированных кадров, их удержание путем четко сформированной процедуры стимулирования и мотивации, использование иерархических принципов. Такой опыт иностранных государств свидетельствует о ценности государственной службы, ее престиже, требовании качественного выполнения должностных обязанностей и удовлетворенности госслужащих своей работой и благосостоянием.

\section{5. Вывод}

Вышеизложенное исследование государственных служащих, работающих в судах зарубежных стран, дает основание сделать вывод о следующем:

1) госслужащие демонстрируют высокий уровень морально-этических норм и нравственных ценностей, высокую ответственность за выполнение служебных обязанностей. Работники судов ценят службу, которая открывает для них перспективу профессионального совершенствования и социального благоустройства;

2) государственная служба за рубежом имеет глубокие исторические корни, представляет для людей, претендующих занять соответствующую должность, престижность, элитарность;

3) высокая продуктивность труда;

4) полное обязательство по отношению к профессиональной деятельности;

5) иерархичность;

6) разнообразие должностей в судебных органах многогранной судебной системы; 
7) репутационный контроль;

8) системы карьеры или закрытой государственной службы. Результатом карьеры является высокий профессионализм человека, полная отдача служению государству, достижение признанного профессионального статуса, получение ряда привилегий (льгот).

Совершенствование системы оплаты труда, порядок организации стимулирования работы государственных служащих для ее высококачественной продуктивности в сфере предоставления ряда судебных услуг, введение новых должностных единиц в штатное расписание аппаратов судов, внедрение общественного и репутационного контроля путем установления оценки деятельности государственных служащих общественностью, поиск других инновационных решений, которые можно почерпнуть из детального изучения зарубежного опыта, может стать ступенью для выведения государственной службы Украины на новый уровень в условиях ее активного реформирования. Таким образом, составление перечня изменений для внесения в действующее законодательство о государственной службе, в частности, касательно служащих аппаратов судов, построенное на основе теоретико-методологического исследования соответствующего опыта стран Европы, станет решением вышеупомянутой проблематики и будет способствовать снятию социальной напряженности - как со стороны общественности, не доверяющей судебной власти в целом, так и со стороны многочисленной когорты работников аппаратов судов, имеющих статус государственных служащих. Совершение таких шагов путем укрепления институции и внедрение надлежащего управления улучшит качество государственного управления.

\section{Ілитература}

Apon M.E., 2016, Gosudarstvennaya sluzhba $v$ zarubezhnykh stranakh: uchebnoe posobie, Sankt-Peterburg || Апон M.Е., 2016, Государственная служба в зарубежных странах: учебное пособие, Санкт-Петербург.

Chernonog E.S., 2008, Gosudarstvennaya sluzhba: istoriya, teoriya i praktika: uchebnoe posobie, Kiev || Черноног Е.С., 2008, Государственная служба: история, теория и практика: учебное пособие, Киев. 
Dubenko S.D., 1999, Gosudarstvennaya sluzhba i gosudarstvennye sluzhashchie v Ukraine: uchebno-metodicheskoe posobie, Kiev || Дубенко С.Д., 1999, Государственная служба и государственные служащие в Украине: учебно-методическое пособие, Киев.

European Judicial Systems, Edition 2012 (2010 Data): Efficiency and Quality of Justice, Council of Europe Publishing.

Francuzskij Kodeks administrativnogo pravosudiya, 2019, Beshe-K. Golovko, E.V. Talapina (eds.), Moskva 2019 || Французский Кодекс административного правосудия, 2019, Беше-К. Головко, Э.В. Талапина (ред.), Москва 2019.

Gosudarstvennoe upravlenie: problemy administrativno-pravovoj teorii i praktiki: nauchnoe posobie, 2003, V.B. Averyanova (ed.), Kiev || Государственное управление: проблемы административно-правовой теории и практики: научное пособие, 2003, В.Б. Аверьянов (ред.), Киев.

Gosudarstvennyj sovet (Conseil d'État) || Государственный совет (Conseil d'État), [электронный ресурс] https://www.conseil-etat.fr/ru [дата доступа: 15.05.2021].

Grekova Zh.V., 2001, Reformirovanie gosudarstvennoj sluzhby kak politiko-administrativnyj process: Opyt Velikobritanii i SSHA v kontekste rossijskikh realij, dis... kand. polit. nauk: 23.00.02, Moskva || Грекова Ж.В., 2001, Реформирование государственной службы как политико-административный процесс: Опыт Великобритании и США в контексте российских реалий, дис... канд. полит. наук: 23.00.02, Москва.

Griniveckaya N.M., 1999, Gosudarstvennaya sluzhba kak socialnyj institut: problemy konceptualnogo analiza, Moskva-Kiev || Гринивецкая Н.М., 1999, Государственная служба как социальный институт: проблемы концептуального анализа, Москва-Киев.

Lapa E.P., 2011, Zaimstvovanie zarubezhnogo opyta v reformirovanii gosudarstvennoj sluzhby Rossii, "Vestnik Buryatskogo gosudarstvennogo universiteta", Vol. 2: Ekonomika i pravo, p. 12-17 || Лапа Е.П., 2011, Заимствование зарубежного опьта в реформировании государственной службы России, «Вестник Бурятского государственного университета», вып. 2: Экономика и право, с. 12-17.

Litvinceva E.A., 2003, Gosudarstvennaya sluzhba $v$ zarubezhnykh stranakh, Moskva || Литвинцева Е.А., 2003, Государственная служба в зарубежньх странах, Москва.

Mirovye modeli gosudarstvennogo upravleniya: opyt dlya Ukrainy, 2012, Yu.V. Kovbasyuk et al. (eds.), Kiev || Мировые модели государственного управления: опьт для Украины, 2012, Ю.В. Ковбасюк и др. (ред.), Киев.

Moldovan V.V., 2012, Sudoustrojstvo. Ukraina, Velikaya Britaniya, Rossijskaya Federaciya, SSHA, FRG, Franciya. Sudebnye organy OON. Nauchnoe posobie, Kiev || Молдован В.В., 2012, Судоустройство. Украина, Великая Британия, Российская Федерация, США, ФРГ, Франция. Судебные органы ООН. Научное пособие, Киев.

Nazarov I.V., 2011, Sudebnye sistemy stran Evropejskogo Soyuza i Ukrainy: genezis i sravnenie, Kharkov || Назаров И.В., 2011, Судебные системы стран Европейского Союза и Украины: генезис и сравнение, Харьков. 
Ogrenchuk A., 2011, Evropejskie standarty gossluzhby. Pravovoj analiz i osobennosti prokhozhdeniya gosudarstvennoj sluzhby $v$ stranakh-chlenakh ES, «Pravo», Vol. 25(704) || Огренчук А., 2011, Европейские стандарты госслужбы. Правовой анализ и особенности прохождения государственной службы в странах-членах EC, «Pravo», вып. 25 (704), [электронный ресурс] https://pravo.ua/articles/ evropejskie-standarty-gossluzhby [дата доступа: 10.05.2021].

Salikov D.Kh., 2018, Gosudarstvennaya sluzhba $v$ V respublike, "Obshchestvo, ekonomika, upravlenie”, Vol. 3, No. 2, p. 95-101 || Саликов Д.Х., 2018, Государственная служба в V республике, «Общество, экономика, управление», т. 3, № 2, c. 95-101.

Ukaz № 92-415 ot 30 aprelya 1992 g. o sozdanii korpusa gosudarstvennykh sluzhashchikh sudebnykh sluzhb kategorij C i D || Указ № 92-415 от 30 апреля 1992 г. о создании корпуса государственных служащих судебных служб категорий С и D, [электронный ресурс] https://www.legifrance.gouv.fr/loda/id/ JORFTEXT000000175617 [дата доступа: 10.05.2021]. 